\title{
Finding the Spaces for Change: A Power Analysis
}

\section{John Gaventa*}

\begin{abstract}
1 Introduction
Around the world, new spaces and opportunities are emerging for citizen engagement in policy processes, from local to global levels. Policy instruments, legal frameworks and support programmes for promoting them abound. Yet, despite the widespread rhetorical acceptance, it is also becoming clear that simply creating new institutional arrangements will not necessarily result in greater inclusion or pro-poor policy change. Rather, much depends on the nature of the power relations which surround and imbue these new, potentially more democratic, spaces.
\end{abstract}

Critical questions are to be asked. Does this new terrain represent a real shift in power? Does it really open up spaces where participation and citizen voice can have an influence? Will increased engagement within them risk simply re-legitimating the status quo, or will it contribute to transforming patterns of exclusion and social injustice and to challenging power relationships? In a world where the local and the global are so interrelated, where patterns of governance and decision making are changing so quickly, how can those seeking pro-poor change decide where best to put their efforts and what strategies do they use?

Whether concerned with participation and inclusion, realising rights or changing policies, more and more development actors seeking change are also becoming aware of the need to engage with and understand this phenomenon called power. Yet simultaneously, the nature and expressions of power are also rapidly changing. The very spread and adoption by powerful actors of the language and discourse of participation and inclusion confuses boundaries of who has authority and who does not, who should be on the 'inside' and who is on the 'outside' of decision-making and policymaking arenas. Changing governance arrangements, which call for 'co-governance' and 'participatory governance' challenge our traditional categories of the rulers and the ruled, the policymakers and the public. The use of terms such as 'partnership' and 'shared ownership' by large, powerful actors like the World Bank and the International Monetary Fund (IMF) invite engagement on a 'level playing field' but obscures inequalities of resources and power. The adoption by multinational corporate actors of notions of 'corporate citizenship', blurs traditional 'us' and 'them' distinctions between economic power holders and those who might negatively be affected by their corporate practices. And in the midst of all of this changing language and discourse, rapid processes of globalisation challenge ideas of 'community' and the 'nation-state', reconfiguring the spatial dynamics of power, and changing the assumptions about the entry points for citizen action.

All of these changes point to the need for activists, researchers, policymakers and donors who are concerned about development and change to turn our attention to how to analyse and understand the changing configurations of power. If we want to change power relationships, e.g. to make them more inclusive, just or pro-poor, we must understand more about where and how to engage. This article shares one approach to power analysis; an approach which has come to be known as the 'power cube' and provides some reflections and examples of how this approach has been applied in differing contexts.

\section{Reflecting on power analysis}

Though everyone possesses and is affected by power, the meanings of power - and how to understand it - are diverse and often contentious (as the articles in this IDS Bulletin illustrate). Some see power as held by actors, some of whom are powerful while others are relatively powerless. Others see it as more pervasive, embodied in a web of relationships and discourses which affect everyone, but which no 
single actor holds. Some see power as a 'zero-sum' concept - to gain power for one set of actors means that others must give up some power. Since rarely do the powerful give up their power easily, this often involves conflict and 'power struggles'. Others see power as more fluid and accumulative. Power is not a finite resource; it can be used, shared or created by actors and their networks in many multiple ways. Some see power as a 'negative' trait - to hold power is to exercise control over others. Others see power to be about capacity and agency to be wielded for positive action.

Power is often used with other descriptive words. Power 'over' refers to the ability of the powerful to affect the actions and thought of the powerless. The power 'to' is important for the capacity to act; to exercise agency and to realise the potential of rights, citizenship or voice. Power 'within' often refers to gaining the sense of self-identity, confidence and awareness that is a precondition for action. Power 'with' refers to the synergy which can emerge through partnerships and collaboration with others, or through processes of collective action and alliance building. ${ }^{1}$

My own view of power was shaped by my own history of engaging with power relations in a particular context. As a young graduate in political science, I began working with grassroots citizens in a remote mining valley of one of the poorest parts of the USA in their efforts to claim political, economic and social rights vis-à-vis government and a Londonbased corporate mine owner. The conventional views of democracy and power in the USA which I had learned in my studies failed to explain the reality I encountered. Though violations of democratic rights, enormous inequalities in wealth and appalling environmental living conditions were to be found everywhere, there was little visible conflict or action for change.

There was something about power which had led not only to defeat where voices had been raised, but also, somehow, over time, the voices had been silenced altogether. ${ }^{2}$ Much of my work then shifted to how citizens recovered a sense of their capacity to act, and how they mobilised to get their issues heard and responded to in the public agenda. For almost 20 years, from the mid-1970s to the mid-1990s, while also teaching and researching at the University of Tennessee, I was practically engaged with a nongovernmental organisation (NGO) working for grassroots empowerment, the Highlander Center based in southern USA. Much of our approach involved finding ways to strengthen the capacity of ordinary citizens and to analyse and challenge the inequalities of power which affected their lives.

After joining the Institute for Development Studies (IDS) in the mid-1990s, I continued to work on processes of citizen participation and engagement in other parts of the world. In the international development field, I discovered a host of approaches for participation in research and learning, advocacy and community mobilisation, poverty assessments and policy processes, local governance and decentralisation, and rights-based and citizenshipbuilding approaches. At the same time, with their increasing acceptance in mainstream development discourse, many of these approaches risked becoming techniques which did not pay sufficient attention to the power relations within and surrounding their use. Increasingly, the work of the Participation Group at IDS and many of our associates began to look for approaches which put an understanding of power back in the centre of our understanding of the concepts and practices of participation.

My own work focused mainly on the intersection of power with processes of citizen engagement in governance at the local, national and global levels. Work with Anne Marie Goetz asked questions about the most important spaces in which citizens could effectively engage, and how to move citizen voice from access, to presence, to influence (Goetz and Gaventa 2001). Work with other colleagues examined how citizens participated in policy spaces surrounding poverty reduction, and concluded with a call for moving from 'from policy to power' (Brock et al. 2004). Through the Development Research Centre on Citizenship, Participation and Accountability, I worked and learned with a research team, led by Andrea Cornwall and Vera Coehlo, which was examining the spaces and dynamics of citizen participation (Cornwall and Coehlo 2004; 2006). Some work, through LogoLink, ${ }^{3}$ focused on citizen participation at the local level. Other work focused on global citizen action (Edwards and Gaventa 2001). In all of these areas, the issues of power and its links with processes of citizen engagement, participation and deepening forms of democracy were always lurking somewhere close to the surface. 
Figure 1 The 'power cube': the levels, spaces and forms of power

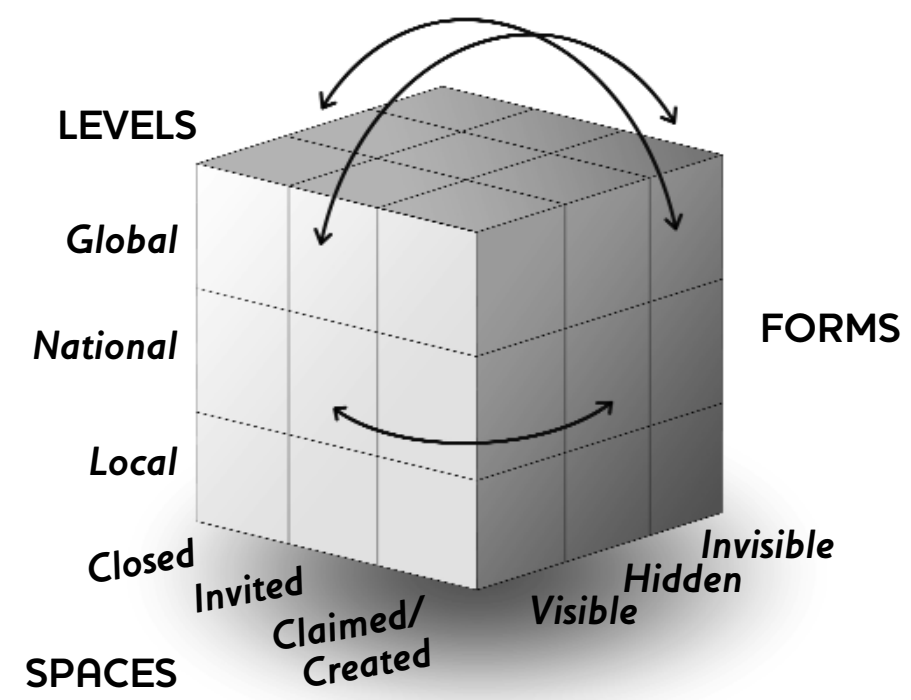

Increasingly, we began to search for approaches which could make the implicit power perspective more explicit, and which would help to examine the interrelationships of the forms of power which we were encountering in different political spaces and settings. Building on my previous work based on the 'three dimensions' of power developed by Steven Lukes (Lukes 1974; Gaventa 1980), I began to argue that Luke's three forms of power must also be understood in relation to how spaces for engagement are created, and the levels of power (from local to global), in which they occur.

Understanding each of these - the spaces, levels and forms of power - as themselves separate but interrelated dimensions, each of which had at least three components within them, these dimensions could be visually linked together into a 'power cube' (Figure 1). By using this framework, I argued, we could begin to assess the possibilities of transformative action in various political spaces. Moreover, the approach could be a tool for reflection by activists and practitioners to map the types of power which we sought to challenge, and to look at the strategies for doing so.

While some thought the 'cube' image (Figure 1) risked being a bit too static in its portrayal of power, for many practitioners, the approach seemed to have some resonance. We have used it with donor agencies as a tool for reflecting on the strategies they use within developing countries, and to encourage selfreflection on the power which they as donor agencies exercise (Development Research Centre 2003). I have shared it in a workshop on political capacity building with NGOs in Indonesia, especially to analyse and reflect on the ways in which they move from working for strengthening local participation, to engaging at the more national level. With my colleagues at Just Associates - who themselves have long experimented with popular education approaches to power analysis - the approach was also used at an international workshop with popular educators, campaigners and development staff from trade unions and international NGOs to discuss how to build links between local knowledge and mobilisation and broader international advocacy work, in order to challenge global economic power (Just Associates 2006). ${ }^{4}$ Most extensively, the framework contributed to an evaluation on 'Assessing Civil Society Participation as supported In-Country by Cordaid, Hivos, Novib and Plan Netherlands 1999-2004', which included applications of the approach in Colombia, Guinea, Guatemala, Uganda and Sri Lanka (Guijt 2005; Gaventa 2005).

In this article, I elaborate further on the different sides, or dimensions of the cube, and then examine their interrelationships. I conclude by sharing further examples of how this approach has been applied for a critical understanding of power. 


\section{Understanding the spaces, places and forms of power}

As mentioned above, the power cube is a

framework for analysing the spaces, places and forms of power and their interrelationship. Though visually presented as a cube, it is important to think about each side of the cube as a dimension or set of relationships, not as a fixed or static set of categories. Like a Rubik's cube, ${ }^{5}$ the blocks within the cube can be rotated - any of the blocks or sides may be used as the first point of analysis, but each dimension is linked to the other. In this presentation, we begin with the dimension of spaces, then move to the levels of power, then conclude by returning to how this relates to the three forms of power earlier developed by Lukes.

\subsection{The spaces for participation ${ }^{6}$}

The notion of 'space' is widely used across the literatures on power, policy, democracy and citizen action. Some writers refer to 'political spaces' as those institutional channels, political discourses and social and political practices through which the poor and those organisations working with them can pursue poverty reduction (Webster and EngbergPetersen 2002). Other work focuses on 'policy spaces' to examine the moments and opportunities where citizens and policymakers come together, as well as 'actual observable opportunities, behaviours, actions and interactions... sometimes signifying transformative potential' (McGee 2004: 16). Other work examines 'democratic spaces' in which citizens can engage to claim citizenship and affect governance processes (Cornwall and Coehlo 2006) In this article, which takes citizen action and participation as its starting point, 'spaces' are seen as opportunities, moments and channels where citizens can act to potentially affect policies, discourses, decisions and relationships that affect their lives and interests.

As Andrea Cornwall's work reminds us, these spaces for participation are not neutral, but are themselves shaped by power relations, which both surround and enter them (Cornwall 2002). Among others, she draws upon French social theorists (Lefebvre, Foucault, Bourdieu) for whom the concept of power and the concept of space are deeply linked. Quoting Lefebvre: "Space is a social product ... it is not simply "there", a neutral container waiting to be filled, but is a dynamic, humanly constructed means of control, and hence of domination, of power' (Lefebvre 1991: 24).
Inherent also in the idea of spaces and places is also the imagery of 'boundary'. Power relations help to shape the boundaries of participatory spaces, what is possible within them, and who may enter, with which identities, discourses and interests. Using the idea of boundary from Foucault and others, Hayward suggests that we might understand power 'as the network of social boundaries that delimit fields of possible action'. Freedom, on the other hand, 'is the capacity to participate effectively in shaping the social limits that define what is possible' (Hayward 1998: 2). In this sense, participation as freedom is not only the right to participate effectively in a given space, but the right to define and to shape that space.

So one dynamic we must explore in examining the spaces for participation is to ask how they were created, and with whose interests and what terms of engagement. While there is much debate on the appropriate terminology for these spaces, our work seems to suggest a continuum of spaces, which include:?

- Closed spaces. Though we want to focus on spaces and places as they open up possibilities for participation, we must realise that still many decision-making spaces are closed. That is, decisions are made by a set of actors behind closed doors, without any pretence of broadening the boundaries for inclusion. Within the state, another way of conceiving these spaces is as 'provided' spaces in the sense that elites (be they bureaucrats, experts or elected representatives) make decisions and provide services to 'the people', without the need for broader consultation or involvement. Many civil society efforts focus on opening up such spaces through greater public involvement, transparency or accountability.

- Invited spaces. As efforts are made to widen participation, to move from closed spaces to more 'open' ones, new spaces are created which may be referred to as 'invited' spaces, i.e. 'those into which people (as users, citizens or beneficiaries) are invited to participate by various kinds of authorities, be they government, supranational agencies or non-governmental organisations' (Cornwall 2002). Invited spaces may be regularised, that is they are institutionalised ongoing, or more transient, through one-off forms of consultation. Increasingly with the rise of approaches to 
participatory governance, these spaces are seen at every level, from local government, to national policy and even in global policy forums.

- Claimed/created spaces. Finally, there are the spaces which are claimed by less powerful actors from or against the power holders, or created more autonomously by them. Cornwall refers to these spaces as 'organic' spaces which emerge 'out of sets of common concerns or identifications' and 'may come into being as a result of popular mobilisation, such as around identity or issuebased concerns, or may consist of spaces in which like-minded people join together in common pursuits' (Cornwall 2002). Other work talks of these spaces as 'third spaces' where social actors reject hegemonic space and create spaces for themselves (Soja 1996). These spaces range from ones created by social movements and community associations, to those simply involving natural places where people gather to debate, discuss and resist, outside of the institutionalised policy arenas.

These are not the only possible spaces - the critical kinds of spaces for engagement will vary across context and historical setting. In various applications and uses, many other relevant terminologies have been added to this continuum, such as 'conquered', 'instigated', or 'initiated' spaces. In work with civil society actors in Colombia, Pearce and Vela (2005) identified a continuum of spaces which included:

- formal by invitation (participation is officially offered in some way)

- formal by right (participation is mandated or legislated)

- created by non-state institutions (e.g. by church, parties, donors)

- created by civil society organisations (CSOs) (e.g. by NGOs or grassroots organisations)

- collective transitory action (such as protests or land occupations).

Whatever the terminology, critical though it is who creates the space - those who create it are more likely to have power within it, and those who have power in one, may not have so much in another.

We must also remember that these spaces exist in dynamic relationship to one another, and are constantly opening and closing through struggles for legitimacy and resistance, co-optation and transformation. Closed spaces may seek to restore legitimacy by creating invited spaces; similarly, invited spaces may be created from the other direction, as more autonomous people's movements attempt to use their own fora for engagement with the state. Similarly, power gained in one space, through new skills, capacity and experiences, can be used to enter and affect other spaces. From this perspective, the transformative potential of spaces for participatory governance must always be assessed in relationship to the other spaces which surround them. Creation of new institutional designs of participatory governance, in the absence of other participatory spaces which serve to provide and sustain countervailing power, might simply be captured by the already empowered elite.

The interrelationships of the spaces also create challenges for civil society strategies of engagement. To challenge 'closed' spaces, civil society organisations may serve the role of advocates, arguing for greater transparency, more democratic structures, or greater forms of public accountability. As new 'invited' spaces emerge, civil society organisations may need other strategies of how to negotiate and collaborate 'at the table', which may require shifting from more confrontational advocacy methods. At the same time, research shows that 'invited spaces' must be held open by ongoing demands of social movements, and that more autonomous spaces of participation are important for new demands to develop and to grow. Spanning these spaces - each of which involves different skills, strategies and resources - is a challenge. In reality, civil society organisations must have the 'staying power' (Pearce and Vela) to move in and out of them over time, or the capacity to build effective horizontal alliances that link strategies across the various spaces for change.

\subsection{Places and levels for participation}

The concern with how and by whom the spaces for participation are shaped intersects as well with debates on the places, or levels where critical social, political and economic power resides. While some work on power (especially that on gender and power) starts with an analysis of power in more private or 'intimate' spaces, much of the work on public spaces for participation involves the contest between local, national and global arenas as locations of power. ${ }^{8}$ There are some that argue that participatory practice must begin locally, as it is in the 
arenas of everyday life in which people are able to resist power and to construct their own voice. There are others who argue that power is shifting to more globalised actors, and struggles for participation must engage at that level. In between, there are debates on the role of the nation state, and how it mediates power; on how the possibilities of local spaces often depend on the extent to which power is legitimated nationally, but shared with the locality. $A$ great deal of work in the area of decentralisation, for instance, discusses the dynamics of power between the locality and the nation state, while other literature argues for the importance of community- or neighbourhood-based associations as key locations for building power 'from below'.

However, a growing body of literature warns us of the dangers of focusing only on the 'local', or the 'national' in a globalising world. Globalisation, it is argued, is shifting traditional understandings of where power resides and how it is exercised, transforming traditional assumptions of how and where citizens mobilise to hold states and non-state actors to account (Tarrow 2005; Batliwala and Brown 2006). Concerns with global governance are producing new extra-national fora in which citizens might be seeking to engage, such as NEPAD (The New Partnership for Africa's Development) or the African Union. Moreover, rather than being separate spheres, the local, national and global are increasingly interrelated. Local forms and manifestations of power are constantly being shaped in relationship to global actors and forces, and in turn, local action affects and shapes global power. Local actors may use global forums as arenas for action (e.g. Narmada Dam; Chiapas) just as effectively - or more effectively than they can appeal to institutions of local governance. Conversely, expressions of global civil society or citizenship may simply be vacuous without meaningful links to local actors and local knowledge.

As in the example of the spaces of participation, this vertical dimension of the places of participation should also be seen as a flexible, adaptable continuum, not as a fixed set of categories. As in the types of spaces, the relevance and importance of levels and places for engagement varies according to the purpose of differing civil society organisations and interventions, the openings that are being created in any given context, etc. In work in Colombia, for instance, civil society organisations identified eight different levels of civil society engagement in the public sphere, each of which has its own types of spaces, including the international, national, departmental, regional/provincial, municipal, communal and neighbourhood levels (Pearce and Vela 2005). Many of these are shaped by the relevant legal frameworks of governmental administration, and may differ across rural and urban communities, yet increasingly, extra-local arenas seem to grow as centres of power and decision making.

For civil society, the changing local, national and regional levels of power pose challenges for where and how to engage. Some focus at the global level, waging campaigns to open the closed spaces of groups like the World Trade Organization (WTO). Other focus more on challenging economic power locally. Yet, the interrelationships of these levels of power with one another suggest that the challenge for action is not only how to build participatory action at differing levels, but how to promote the democratic and accountable vertical links across actors at each level. As Pieterse (1997) puts it, 'this involves a double movement, from local reform upward and from global reform downward - each level of governance, from the local to the global, plays a contributing part' (quoted in Mohan and Stokke 2000: 263). At the same time, a growing concern among civil society organisations has to do with the lack of such vertical links between those organisations doing advocacy at an international level, often led or supported by international NGOs, with those working to build social movements or alternative strategies for change at the more local levels (Batliwala 2002).

This subject was pursued further in a 2005 workshop at IDS on 'Citizen Action, Knowledge and Global Economic Power', where the power cube approach was to used to reflect and analyse the different kinds of civil society initiatives going on at different levels. In doing so, the disconnections between those who are speaking at the global level and those who are experiencing problems of poverty or economic injustice at the local level were highlighted. The workshop then focused on ways of overcoming the disconnections.

\subsection{The forms and visibility of power across spaces and places}

As we examine the relationships of place and space vis-à-vis participation, we must also examine the dynamics of power that shape the inclusiveness of 


\section{Box 1 Forms of power}

\section{Visible power: observable decision making}

This level includes the visible and definable aspects of political power - the formal rules, structures, authorities, institutions and procedures of decision making ... Strategies that target this level are usually trying to change the 'who, how and what' of policymaking so that the policy process is more democratic and accountable, and serves the needs and rights of people and the survival of the planet.

\section{Hidden power: setting the political agenda}

Certain powerful people and institutions maintain their influence by controlling who gets to the decision-making table and what gets on the agenda. These dynamics operate on many levels to exclude and devalue the concerns and representation of other less powerful groups ... Empowering advocacy strategies that focus on strengthening organisations and movements of the poor can build the collective power of numbers and new leadership to influence the way the political agenda is shaped and increase the visibility and legitimacy of their issues, voice and demands.

\section{Invisible power: shaping meaning and what is acceptable}

Probably the most insidious of the three dimensions of power, invisible power shapes the psychological and ideological boundaries of participation. Significant problems and issues are not only kept from the decision-making table, but also from the minds and consciousness of the different players involved, even those directly affected by the problem. By influencing how individuals think about their place in the world, this level of power shapes people's beliefs, sense of self and acceptance of the status quo - even their own superiority or inferiority. Processes of socialisation, culture and ideology perpetuate exclusion and inequality by defining what is normal, acceptable and safe. Change strategies in this area target social and political culture as well as individual consciousness to transform the way people perceive themselves and those around them, and how they envisage future possibilities and alternatives.

Adapted by Just Associates from VeneKlasen and Miller (2002).

participation within each. Here, much of the literature of power is concerned with the degree to which conflict over key issues and the voices of key actors are visible in given spaces and places. In earlier work, building on work by Lukes (Lukes 1974; Gaventa 1980) I explored the differences between:

- more pluralist approaches to power, in which contests over interests are assumed to be visible in public spaces, which in turn are presumed to be relatively open

- a second form of power, in which the entry of certain interests and actors into public spaces is privileged over others through a prevailing 'mobilisation of bias' or rules of the game; and

- a third form of power, in which conflict is more invisible, through internalisation of powerlessness, or through dominating ideologies, values and forms of behaviour.

In more recent work which in turn builds upon this approach, VeneKlasen and Miller argue more simply for distinguishing between the visible, hidden and invisible (or internalised) forms of power (see Box 1).

The importance of this for how we analyse the dynamics of participation in differing spaces and places is relatively obvious. Historically, many pluralist studies of power have mainly examined power in its visible manifestations. One looked at who participated, who benefited and who lost in order to see who had power. But as we have seen, power in relationship to place and space also works to put boundaries on participation, and to exclude certain actors or views from entering the arenas for participation in the first place. Or power, in its more insidious forms, may be internalised in terms of one's values, self-esteem and identities, such that voices in visible places are but echoes of what the power holders who shaped those places want to hear. Such power analysis points again to the importance of establishing the preconditions of participation in order for new institutional spaces to lead to change in the status quo. Without prior awareness building 
so that citizens possess a sense of their own right to claim rights or express voice, and without strong capacities for exercising countervailing power against the 'rules of the game' that favour entrenched interests, new mechanisms for participation may be captured by prevailing interests.

As in the other dimensions of the power cube, the multiple forms of power also pose challenges for civil society actors trying to change power relations. Some groups may focus on advocacy approaches, challenging the visible forms of power in visible arenas through public debate, informed research and working to influence public representatives. Others may focus on mobilising and collective action strategies, which work to challenge barriers which prevent certain actors and forms of knowledge from entering public arenas in the first place. Yet, others may focus more on changing the invisible, internalised forms of power, through awareness and consciousness-building campaigns. While often these are different strategies involving different organisations and interventions to change power, in fact strategies are also needed which link across them. For instance, a policy victory in the visible arena of power may be important, but may not be sustained, if those outside the arena are not aware that it has occurred and how it relates to their interests, or are not mobilised to make sure that other hidden forms of power do not preclude its implementation.

\section{The interrelationship of the spaces, places and \\ forms of power}

As argued above, the dynamics of power depend very much on the type of space in which it is found, the level at which it operates and the form it takes. Moreover, as has been suggested, along each dimension, any sustained and effective change strategy must concern itself with how to build and sustain effective change across the full continuum. Transformative, fundamental change happens, I suggest, in those rare moments when social movements or social actors are able to work effectively across each of the dimensions simultaneously, i.e. when they are able to link the demands for opening previously closed spaces with people's action in their own spaces; to span across local and global action, and to challenge visible, hidden and invisible power simultaneously. Just like the Rubik's cube, successful change is about getting each of the pieces on each dimension of the cube to align with each other, simultaneously.
'Alignment' of strategies for change is a huge challenge, both across each of the dimensions of the cube, but also made more difficult by their interaction. For instance, along the spaces dimension, while many groups seeking action work either on opening closed spaces through demanding more transparency or supporting internal reform, or on building social movements and mobilisation in claimed space, much research suggests that it is effective when horizontal alliances are built across these spaces that real change occurs. Similarly, advocacy and change strategies must often build vertical alliances across local, national and global levels to make sure that changes are meaningful at each level. And, those seeking not only to influence policies in the public arena, but also to change power relations more fundamentally, must simultaneously think about winning the issue, mobilising to broaden the political space, and building awareness of those who are excluded. Rather than any single strategy, an ensemble of strategies, which work together and not against each other, are required to fully challenge these sets of power relationships.

Moreover, while it is difficult enough for those seeking change to work across the range of any single dimension of the cube, in fact the dimensions are simultaneously interacting to affect the other. Strategies for alignment along one axis may contribute to misalignment on another. Those who study the Rubik's cube argue that there are literally billions of different positions ${ }^{9}$ that the blocks of the cube may have, illustrating the complexity and permutations in which power can take across space, place and form in any given context. The local, national and global agenda affects the opening and closure of invited spaces; the visibility of power is shaped by who creates the space; in turn prior participatory experiences which have helped to overcome forms of invisible and hidden power, may strengthen the possibilities for success of new institutional designs for participation.

For any given issue or action, there is no single strategy or entry point. Much depends on navigating the intersection of the relationships, which in turn can either contribute to new misalignments and distortions of power, or simultaneously creates new boundaries of possibility for strategic action. For instance, linking local-national-global campaigns to open up previously closed spaces may be important, 
but in so doing, they may re-enforce forms of hidden and invisible power, if they simultaneously exclude certain potential actors or forms of knowledge. On the other hand, the opening of previously closed local spaces can contribute to new mobilisations and conscientisation, which may have the potential to open other spaces more widely, and to create momentum for change at national or global levels. Like a Rubik's cube, sometimes the dimensions may appear chaotic, random and confused; at other times they may appear as if alignments will be possible.

In fact, those who study the Rubik's cube also tell us that any cube can be re-aligned in a maximum of 29 moves, taken in the right sequence. While not wanting to reduce social change to a formulaic solution, this does suggest that those seeking to challenge power in all of its spaces, levels and forms need to search not for one solution, but to build multiple, linked strategies and in different sequences, depending on the starting point in any given context. The challenge is to understand what these strategies might be, and how they can be linked to realign all of the dimensions of power. That is when transformative change might really occur.

The power cube approach does not do this for us. It is not a checklist, for example the idea is not to check off each box, as the significance, dynamics and interrelationships of the dimensions are constantly changing and vary enormously from one context to another. Nor is it prescriptive, valorising local, claimed spaces over the distant global, closed spaces, for it suggests that each has forms of visible, hidden and invisible power within them. Rather, the power cube is meant to be more of an analytical device, which can be used - along with other approaches to reflect on and analyse how strategies for change in turn change power relations.

In numerous settings, we have used the approach to encourage such reflections with development actors on their strategies for change, and indeed their own power and position within them. In work in Nigeria, the use of an early formation of the approach helped us to see how struggles to open up the national Poverty Reduction Strategy Paper (PRSP) process, which itself came through global interventions, contributed to challenging traditionally closed and top-down approaches to poverty policy. At the same time, by remaining disconnected from many local actors and from many existing movements challenging poverty in their own spaces, the donor agenda for more participation and inclusion in the national policy process had the inadvertent affect of creating a greater sense of exclusion for some other local and social movement actors (Brock et al. 2004).

In using the power cube with international NGOs, reflections using the power cube approach helped to see the need and possibilities of greater interconnections between global campaigning, often done by professional advocates working in a rapidly changing policy environment, and local development work, where strategies were more likely to encourage people to mobilise and speak for themselves, and to challenge invisible and internalised forms of power.

In an evaluation of the civil society participation work of Dutch international non-governmental organisations (INGOs), the approach was used with local civil society groups in Sri Lanka, Uganda and Colombia to encourage local groups to reflect on the kinds of spaces in which they were participating, the strategies they used in each and how they interacted (Dutch CSO). And in work with donors, the approach has been used to reflect on what kinds of change donors sought to support, and then placing themselves in the power cube, what strategies they actually engaged with, and how in doing so, they themselves became part of the power equation (Guijt 2005).

In conclusion, even if the power cube approach does not tell us how to align our efforts, if it can be used by actors seeking to change the world to reflect on where and how they do so, and how they work across boundaries with others who are also working for change, then perhaps the alignment of efforts for transforming power will become more possible. In this sense, reflections on power, and reflections by change agents on how their work affects power relationships in all of its dimensions, is perhaps the first step in making more visible, power's most hidden and invisible forms. 


\section{Notes}

* A similar version of this article has been prepared for the Dutch CFA evaluation, 'Assessing Civil Society Participation', coordinated by Irene Guijt (2005) of Learning by Design, and supported by Cordaid, Hivos, Novib and Plan Netherlands and the Power, Participation and Change Programme of the Participation Group at the Institute of Development Studies. My thanks to the many colleagues from the 'Civil Society Participation' evaluation, the Participation Group, Just Associates, and others from whom I have learned in using and discussing the 'power cube' approach.

1 For further development of these debates, see VeneKlasen and Miller (2002) and Kabeer (1994).

2 For the account of this work, see Gaventa (1980).

3 See the LogoLink website for work on citizen participation and local governance, www.ids.ac.uk/logolink/index.htm (accessed 7 August 2006)

\section{References}

Batliwala, Srilatha (2002) 'Grassroots Movements as Transnational Actors: Implications for Global Civil Society', Voluntas: International Journal of Voluntary and Nonprofit Organizations 13.4: 393-409

Batliwala, Srilatha and Brown, David L. (eds) (2006) Transnational Civil Society: An Introduction, Bloomfield: Kumarian Press

Brock, K., Cornwall, A. and Gaventa, J. (2001) Power, Knowledge and Political Spaces in the Framing of Poverty Policy, IDS Working Paper 143, Brighton: IDS

Brock, K., McGee, R. and Gaventa, J. (eds) (2004) Unpacking Policy: Actors, Knowledge and Spaces in Poverty Reduction, Kampala: Fountain Press

Cornwall, A. (2002) Making Spaces, Changing Places: Situating Participation in Development, IDS Working Paper 170, Brighton: IDS

Cornwall, A. and Coehlo, V. (eds) (2006) Spaces for Change? The Politics of Citizen Participation in New Democratic Arenas, London: Zed Books

Cornwall, A. and Coehlo, V. (eds) (2004) 'New Democratic Spaces?', IDS Bulletin 35.2 (see also www.drc-citizenship.org)

Development Research Centre, Rights and Power Workshop Report (2003), www2.ids.ac.uk/ drccitizen/docs/r\&pworkshopreportfinal.pdf (accessed 7 August 2006)
4 Workshop on 'Citizen Action, Knowledge and Global Economic Power: Reflecting on Current Practices and Challenges Ahead, organised by Just Associates, Action Aid and the IDS Participation Group, 1-3 August 2005 (Just Associates 2006).

5 Rubik's cube refers to a mechanical cube invented in 1974 by the Hungarian sculptor and professor of architecture Ernö Rubik, and marketed widely as a puzzle. The sides of the cube can rotate, though the whole remains intact.

6 The following sections draw heavily on earlier papers on the power cube, as cited in VeneKlasen and Miller (2002) and Kabeer (1994).

7 These ideas have developed from Cornwall (2002); Brock et al. (2001) and Brock et al. (2004).

8 In this article, the 'power cube' focuses primarily on power in the 'public sphere', while recognising that this approach is incomplete.

9 More specifically, about 43 quintillion, or $43,252,003,274,489,856,000$, according to Wikipedia!

Edwards, M. and Gaventa, J. (2001) Global Citizen Action, Boulder; Colorado: Lynne Reinner Publishers

Gaventa, J. (2005) 'Reflections on the Uses of the 'Power Cube, Approach for Analyzing the Spaces, Places and Dynamics of Civil Society Participation and Engagement', prepared for Assessing Civil Society Participation as Supported In-Country by Cordaid, Hivos, Novib and Plan Netherlands 1999-2004, The Netherlands: MFP Breed Netwerk

Gaventa, J. (2004) 'Towards Participatory Governance: Assessing the Transformative Possibilities', in S. Hickey and G. Mohan (eds), From Tyranny to Transformation, London: Zed Books

Gaventa, J. (1980) Power and Powerlessness: Quiescence and Rebellion in an Appalachian Valley, Oxford: Clarendon Press

Goetz, A.M. and Gaventa, J. (2001) From Consultation to Influence: Bringing Citizen Voice and Client Focus into Service Delivery, IDS Working Paper 138, Brighton: IDS

Guijt, I. (2005) 'Synthesis Report of Dutch CFA Programme Evaluation', Assessing Civil Society Participation as Supported In-Country by Cordaid, Hivos, Novib and Plan Netherlands 1999-2004, The Netherlands: MFP Breed Netwerk

Hayward, C.R. (1998) 'De-Facing Power', Polity 31.1: 1-22 
Just Associates (2006) Citizen Engagement and Global Economic Power Workshop Report, Washington DC: Just Associates

Kabeer, N. (1994) Reversed Realities: Gender Hierarchies in Development Thought, London: Verso

Lefebvre, H. (1991) The Production of Space, London: Verso

Lukes, S. (1974) Power: A Radical View, London: Macmillan (reprinted 2004, Basingstoke: Palgrave Macmillan)

McGee, R. (2004) 'Unpacking Policy: Actors, Knowledge and Spaces', in K. Brock, R. McGee and J. Gaventa (eds), Unpacking Policy: Actors, Knowledge and Spaces in Poverty Reduction, Kampala: Fountain Press: 1-26

Mohan, G. and Stokke, K. (2000) 'Participatory Development and Empowerment: The Dangers of Localism', Third World Quarterly 21.2: 247-68

Pearce, J. and Vela, G. (2005) 'Colombia Country Report for the Dutch CFA Programme
Evaluation', Assessing Civil Society Participation as Supported In-Country by Cordaid, Hivos, Novib and Plan Netherlands 1999-2004, The Netherlands: MFP Breed Netwerk

Pieterse, J. (1997) 'Globalisation and Emancipation: From Local Empowerment to Global Reform', New Political Economy 2.1: 79-92

Soja, E. (1996) Third Space: Journeys to Los Angeles and Other Imagined Places, Cambridge, MA: Blackwell

Tarrow, S. (2005) The New Transnational Activism, Cambridge: Cambridge University Press

VeneKlasen, L. and Miller, V. (2002) A New Weave of People, Power and Politics: the Action Guide for Advocacy and Citizen Participation, Oklahoma: World Neighbors

Webster, N. and Engberg-Petersen L. (2002) (eds) In the Name of the Poor: Contesting Political Space for Poverty Reduction, London: Zed Books 